\title{
El Código Penal Militar: ámbito subjetivo de aplicación
}

\author{
The Military Criminal Code: subjective scope of application
}

\author{
Dr. Juan POZO VILCHES \\ Fiscal Jefe de la Sala Quinta \\ del Tribunal Supremo
}

Resumen: La competencia de la Jurisdicción Militar es una de las cuestiones más debatidas desde la época de la Transición democrática. Desde entonces se ha tratado de limitar su competencia al ámbito estrictamente castrense. En 2016 entró en vigor el vigente Código Penal Militar, una norma bastante desconocida para la gran mayoría de los operadores jurídicos. En el presente trabajo examinaremos el ámbito subjetivo de aplicación de esta norma, que, como veremos, se aplica no solo a militares, sino también a civiles, ya se cometa el delito en tiempos de paz o de conflicto armado.

Abstract: The jurisdiction of the military courts is one of the most debated issues from the times of the democratic Transition. Since then, many attempts have been made to limit its jurisdiction to the strictly military scope. Although the current Military Criminal Code entried in force in 2016, it remains quite unknown to the vast majority of legal operators. In this paper we will examine the subjective scope of application of this Code, which, as we shall see, applies not only to military personnel, but also to civilians, whether the crime is committed in peacetime or during an armed conflict.

Palabras clave: Transición democrática. Constitución española. Ámbito estrictamente castrense. Código Penal Militar. Jurisdicción Militar. Tribunales militares.

Keywords: Democratic transition. Spanish Constitution. Scope strictly military. Military Criminal Code. Military jurisdiction. Military courts.

\section{Sumario:}

I. Antecedentes.

II. El delito militar. 


\section{III. Ámbito subjetivo de aplicación.}

1.1. Militares profesionales.

1.2. Miembros de la Guardia Civil.

1.3. Reservistas.

1.4. Alumnos.

1.5. Personal asimilado o con consideración militar.

1.6. Capitanes, Comandantes y miembros de la tripulación de buques o aeronaves no militares, y prácticos a bordo de buques de guerra y buques de la Guardia Civil.

1.7. Prisioneros de guerra.

\section{Conclusiones.}

Recibido: agosto 2020.

Aceptado: octubre 2020. 


\section{ANTECEDENTES}

Al promulgarse la Constitución de 1978, se encontraba vigente en España, en el ámbito de la Jurisdicción castrense, el Código de Justicia Militar de 17 de julio de 1945 (CJM). Esta norma se encontraba totalmente obsoleta y desfasada. Es más, ya había nacido vieja, pues se limitaba a refundir en un solo texto, normas de finales del siglo XIX, como el Código de Justicia Militar de 1890, el Código Penal de la Marina de Guerra de 1888, la Ley de Organización y atribuciones de los Tribunales de Marina de 1894, la Ley de Enjuiciamiento Militar de Marina de 1894 y otras leyes procesales.

El CJM de 1945 constaba de 1.072 artículos, y se dividida en tres Tratados ("Organización y atribuciones de los Tribunales Militares", "Leyes Penales" y "Procedimientos militares"), que regulaban cuestiones orgánicas, procesales, penales y disciplinarias. Otorgaba a la Jurisdicción militar una competencia desmesurada, que se determinaba:

a) Por razón del delito: la Jurisdicción militar conocía no solo de los delitos contenidos en el CJM, sino también determinados delitos contenidos en el Código Penal (CP) y en leyes especiales, y ya fuera el autor militar o civil.

b) Por razón del lugar en que se cometía: la Jurisdicción militar no solo conocía de los delitos cometidos en instalaciones militares (cuarteles, campamentos, aeródromos...), sino también de los cometidos en el mar territorial, en el espacio aéreo sometido a soberanía española, o incluso en el Protectorado de Marruecos.

c) Por razón de la persona: la Jurisdicción militar conocía de los delitos cometidos contra militares (en activo o reserva), prisioneros de guerra, civiles que siguiesen a los Ejércitos en campaña..., así como de los delitos cometidos por militares, salvo que se tratara de alguno de los delitos enumerados en el art. 16 CJM. 
Durante la Transición pronto surgió la idea de acometer una profunda reforma del CJM, principalmente de su ámbito competencial, ya que este era incompatible con los nuevos tiempos. Y en los Pactos de la Moncloa de 1977 se acordó restringir los tres criterios competenciales que aplicaba el CJM ${ }^{1}$.

En 1978 se promulgó la Constitución, y en su art. 117.5, dentro del título dedicado al Poder Judicial, se incluyó la única referencia que nuestra Carta Magna dedica a la Jurisdicción militar: "La ley regulará el ejercicio de la jurisdicción militar en el ámbito estrictamente castrense y en los supuestos de estado de sitio, de acuerdo con los principios de la Constitución".

Ahora bien, ¿qué significaba "ámbito estrictamente castrense”? ¿Cuál era su verdadero alcance? Existían dos posturas al respecto ${ }^{2}$ :

- Los que consideraban que la Jurisdicción militar debía limitarse exclusivamente a los delitos militares que figurasen en el correspondiente Código.

- Los que entendían que la Jurisdicción militar debía conocer de los delitos militares contenidos en el correspondiente Código, así como aquellos otros delitos que, sin ser propiamente militares, afectasen al buen régimen y servicio de las Fuerzas Armadas o a los intereses militares.

Mediante Ley Orgánica 9/1980, de 6 de noviembre, se modificó, por fin, el CJM. Se trató de una reforma importante (abarcó 106 artículos), y trató,

\footnotetext{
${ }^{1}$ El apartado VII del Acuerdo sobre el Programa de Actuación Política y Jurídica, aprobado el 27 de octubre de 1977, dedicado al CJM, decía lo siguiente:

"Reconsideración de sus límites en relación con la competencia de la jurisdicción militar:

1. Por razón de delito: resolver la dualidad de tipificaciones entre el Código Penal Común y el Código de Justicia Militar, restringiéndose éste al ámbito de los delitos militares.

2. Por razón de lugar: limitar la competencia de la jurisdicción militar a los actos cometidos en centros o establecimientos o lugares estrictamente militares.

3. Por razón de la persona: revisar los supuestos de desafuero y los términos en que se resuelve la competencia cuando concurre personal militar y no militar en unos mismos hechos que no constituyan delito militar.

4. Sometimiento a los Tribunales ordinarios de las Fuerzas de Orden Público, cuando actúen en el mantenimiento del mismo.

5. Fortalecimiento de las garantías procesales y de defensa en los procedimientos de la jurisdicción militar".

${ }^{2}$ Para un estudio completo del tema, v. FERNÁNDEZ SEGADO, F., "La reforma del ámbito competencial de la Jurisdicción Militar", en Cuadernos de estrategia (Madrid), 50 (1992) 74. CALDERÓN SUSIN, E., "Comentario de urgencia al Proyecto de Código Penal Militar", en Cuadernos de la Facultad de Derecho de la Universidad de Palma de Mallorca (Palma de Mallorca), 9 (1984) 11. PÉREZ ESTEBAN, F., "La competencia de la jurisdicción militar: lo estrictamente castrense", en La Ley Penal (Madrid) 7 (2004) 2. VALENCIANO ALMOYNA, J. "La reforma de la justicia militar en España durante la Transición", en Reis: Revista Española de Investigaciones Sociológicas (Madrid) 36 (1986) 141.
} 
entre otras cuestiones, de reducir la desmedida competencia que hasta entonces había tenido la Jurisdicción Militar. Así, por ejemplo, los delitos comunes cometidos por militares serían conocidos, a partir de entonces, no por la Jurisdicción militar, sino por la Jurisdicción ordinaria "cuando los hechos no afectaren al buen régimen y servicio de las Fuerzas Armadas".

La Ley Orgánica 6/1985, de 1 de julio, del Poder Judicial, va a dar un paso más a la hora de delimitar la competencia de la Jurisdicción militar. Y se decantará claramente por un criterio material: la Jurisdicción militar se limitará a los delitos militares contenidos en el Código Penal Militar ${ }^{3}$. En efecto, su art. 3.2 disponía lo siguiente:

"La competencia de la jurisdicción militar quedará limitada al ámbito estrictamente castrense respecto de los hechos tipificados como delitos militares por el Código Penal Militar y a los supuestos de estado de sitio, de acuerdo con la declaración de dicho estado y la Ley Orgánica que lo regula, sin perjuicio de lo que se establece en el art. 9, apartado 2, de esta Ley".

Por tanto, la Ley Orgánica del Poder Judicial entendía que el "ámbito estrictamente castrense" se limitaba únicamente a los delitos militares, lo que suponía una clara restricción de las normas competenciales que aún mantenía el CJM.

Por fin, mediante Ley Orgánica 13/1985, de 9 de diciembre, se aprobó el Código Penal Militar (CPM-1985) ${ }^{4}$. Este Código derogó el CJM, pero solo su Tratado II ("Leyes penales") $)^{5}$. Simultáneamente al Código, se aprobó la Ley Orgánica 14/1985, de 9 de diciembre, de modificación del Código Penal y de la Ley Orgánica 8/1984, en correlación con el Código Penal Militar, con el fin de evitar que algunos delitos, antes castigados en el CJM, quedasen impunes, al desaparecer de la legislación penal militar.

El CPM-1985, a pesar de ser una norma sustantiva, hará referencia a la competencia de la Jurisdicción militar. En su disposición derogatoria, y en

\footnotetext{
${ }^{3}$ Código que, por cierto, aún no se había aprobado.

${ }^{4}$ El CPM-1985 constaba de 197 artículos, una disposición adicional, cinco transitorias, una derogatoria y una final. Está dividido en dos Libros: Libro I (arts. 1 a 48) relativo a las disposiciones generales; Libro II (arts. 49 a 197) relativo a los delitos en particular.

${ }^{5}$ Los demás Tratados del CJM subsistirán unos años más. En 1987, dos años después del CPM-1985, se aprobó la Ley Orgánica 4/1987, de 15 de julio, de competencia y organización de la Jurisdicción Militar, que derogará el Tratado I del CJM; y en 1989 se aprobó la Ley Orgánica 2/1989, de 13 de abril, Procesal Militar, que derogará el Tratado III del CJM.
} 
consonancia con lo dispuesto en la Ley Orgánica del Poder Judicial, establecerá lo siguiente:

“Queda derogado el Tratado II «Leyes Penales» del Código de Justicia Militar de 17 de julio de 1945 en cuanto se refiere a las mismas, así como cuantas disposiciones se opongan a lo establecido en esta Ley Orgánica, especialmente aquellas referidas a la aplicación por la Jurisdicción Militar de criterios distintos del de competencia por razón del delito.

En el año 2015 se aprobó un nuevo Código Penal Militar ${ }^{6}$ (CPM) mediante Ley Orgánica 14/2015, de 14 de octubre, que derogó el CPM-1985, y es el que actualmente se encuentra en vigor. Es una norma de menor extensión que el CPM-1985, debido a dos razones:

- A la aplicación supletoria del CP común 7 , lo que ha permitido suprimir del CPM numerosas disposiciones del Libro Primero dedicado a las "Disposiciones Generales" (de los 48 artículos del CPM de 1985, se ha pasado a solo 23 artículos).

- A la reducción del Libro Segundo, dedicado a los delitos en particular (de los 148 artículos del CPM de 1985, se ha pasado a solo 62 artículos).

\section{EL DELITO MILITAR}

El art. 1 CPM dispone que el citado Código "será de aplicación a las infracciones que constituyan delitos militares". Y son delitos militares "las acciones u omisiones dolosas o imprudentes previstas en el Libro Segundo de este Código" (art. 9.1 CPM).

\footnotetext{
${ }^{6}$ Consta de 85 artículos, dos disposiciones adicionales, cuatro transitorias, una derogatoria y ocho finales. Está dividido en dos Libros: Libro I (arts. 1 a 23) relativo a las disposiciones generales; Libro II (arts. 24 a 85) relativo a los delitos y sus penas.

Los motivos que impulsaron la redacción de un nuevo CPM fueron, entre otro, el tiempo transcurrido desde la aprobación del CPM anterior (30 años), la profunda transformación de las Fuerzas Armadas en esos años (con la profesionalización de sus miembros y la supresión del servicio militar obligatorio), y la necesidad de configurar el CPM como una norma complementaria del CP común, y no "parcialmente complementaria", como ocurría con el CPM-1985.

${ }^{7}$ Aspiración que también pretendía el CPM-1985, pero no consiguió del todo, al haberse aprobado dicho Código diez años antes que el CP común, lo que originaba desfases e incoherencias entre las dos normas. Vid. CALDERÓN SUSIN, "Comentario de urgencia al Proyecto de Código Penal Militar", o. c. 11. RODRÍGUEZ-VILLASANTE Y PRIETO, J.L., "La reforma de la organización de la justicia militar española en la transición y consolidación democrática", en $L a$ albolafia: revista de humanidades y cultura (Madrid), 14 (2018) 84.
} 
Pero no solo son delitos "militares" los previstos en el Libro Segundo del CPM, sino también son delitos "militares" ciertas infracciones contenidas en el CP común. En efecto, el art. 9.2 CPM dispone que asimismo son delitos "militares" cualesquiera otras acciones u omisiones cometidas por un militar y tipificadas en el Código Penal como:

a) Delitos de traición y delitos contra las personas y bienes protegidos en caso de conflicto armado, incluidas las disposiciones comunes, siempre que se perpetraren con abuso de facultades o infracción de los deberes establecidos en la Ley Orgánica 9/2011, de 27 de julio, de derechos y deberes de los miembros de las Fuerzas Armadas, o en la Ley Orgánica $11 / 2007$, de 22 de octubre, reguladora de los derechos y deberes de los miembros de la Guardia Civil.

b) Delito de rebelión, en caso de conflicto armado internacional.

Por tanto, para que estos delitos previstos en la legislación penal común tengan la consideración de delitos "militares", y por tanto sometidos a la Jurisdicción militar, se requiere lo siguiente:

1. Que el sujeto activo del delito sea un militar. Y son militares, a efectos del CPM, los individuos mencionados en su art. 2, que veremos más adelante.

2. Que se trate de alguno de los siguientes delitos del CP común:

a) Delito de traición, previsto en los arts. 581 y siguientes del CP común, siempre que se perpetre con abuso de facultades o infracción de los deberes establecidos en la Ley Orgánica 9/2011 (en el caso de miembros de las Fuerzas Armadas) o en la Ley Orgánica 11/2007 (en el caso de miembros de la Guardia Civil).

b) Delitos contra las personas y bienes protegidos en caso de conflicto armado, incluidas las disposiciones comunes, previstos en los arts. 608 y siguientes del CP común, siempre que se perpetre con abuso de facultades o infracción de los deberes establecidos en la Ley Orgánica 9/2011 (en el caso de miembros de las Fuerzas Armadas) o en la Ley Orgánica 11/2007 (en el caso de miembros de la Guardia Civil).

c) Delito de rebelión, previsto en los arts. 472 y siguientes del CP común, en caso de conflicto armado internacional.

Ahora bien, delito militar no es sinónimo de delito cometido por un militar, sino que también es posible que un civil cometa un delito militar. Lo determinante 
no es la condición militar del sujeto activo del delito, sino que resulten lesionados bienes jurídicos de carácter militar. Como dice Quevedo González, "lo que determina la competencia de la Jurisdicción militar no es la profesión del acusado, sino la naturaleza del delito" ${ }^{8}$.

Por tanto, podemos distinguir lo siguiente:

a) En tiempo de paz: la Jurisdicción militar es competente para conocer de los siguientes delitos del $\mathrm{CPM}^{9}$ :

- Los delitos militares propios (es decir, aquellos en los que el tipo requiere que el sujeto activo sea un militar). La inmensa mayoría de los 61 artículos que componen el Libro Segundo del CPM comienzan con expresiones como "el militar que...", "los militares que...", "el centinela que..." o "el superior que...", expresiones que implican, inexorablemente, que el sujeto activo del delito solo puede ser un miembro de las Fuerzas Armadas.

- En cuanto a los delitos militares impropios (es decir, aquellos en los que el tipo no exige que el sujeto activo sea un miembro de las Fuerzas Armadas), la competencia de la Jurisdicción militar es excepciona $1^{10}$. Este tipo de delitos comienzan con expresiones como "el que..." o "el particular o empresario que...". En concreto son los siguientes delitos: allanamiento de establecimiento militar o vulneración de las medidas de seguridad (art. 29); delitos contra centinela (art. 34); delitos previstos en los arts. 550 a 556 del Código Penal contra autoridad militar, fuerza armada o policía militar cometidos en el curso de una operación internacional coercitiva o de paz (art. 35.2); cooperación a la inutilización voluntaria y simulación para eximirse del servicio (art. 59); hurto, robo,

${ }^{8}$ QUEVEDO GONZÁLEZ, J., "El civil ante la Jurisdicción Militar: especial referencia a los delitos contra los medios o recursos de la Defensa Nacional", en Jornadas de especialistas en la jurisdicción militar, Madrid, enero 2018, p. 6.

${ }^{9}$ El art. 12 de la Ley Orgánica 4/1987, de 15 de julio, de competencia y organización de la Jurisdicción Militar, establece la competencia de la Jurisdicción militar en tiempo de paz.

${ }^{10}$ Como dijo la Sentencia del Tribunal Constitucional 60/1991, de 14 de marzo, "como jurisdicción especial penal, la jurisdicción militar ha de reducir su ámbito al conocimiento de delitos que puedan ser calificados como de estrictamente castrenses, concepto que ha de ponerse en necesaria conexión con la naturaleza del delito cometido; con el bien jurídico o los intereses protegidos por la norma penal, que han de ser estrictamente militares, en función de los fines que constitucionalmente corresponden a las Fuerzas Armadas y de los medios puestos a su disposición para cumplir esa misión (arts. 8 y 30 C.E.); con el carácter militar de las obligaciones o deberes cuyo incumplimiento se tipifica como delito, $\mathrm{y}$, en general, con que el sujeto activo del delito sea considerado uti miles, por lo que la condición militar del sujeto al que se imputa el delito ha de ser también un elemento relevante para definir el concepto de lo estrictamente castrense". 
apropiación indebida o daños sobre material de guerra o armamento (art. 82.3); receptación (art. 85), y los cometidos contra la Administración de Justicia Militar (Disposición Final Primera).

Como dijo la Sentencia de la Sala Quinta del Tribunal Supremo de 23 de enero de 1992, "aun cuando los delitos tipificados como militares en el Código Penal Militar vigente, en su inmensa mayoría sólo pueden, en tiempo de paz, ser cometidos por militares, hay un reducido número de ellos (...) que también son competencia de la Jurisdicción militar si los comete persona no militar, en razón de ser conveniente una autónoma tutela especializada por los intereses inherentes a la institución castrense que se intenta proteger".

No obstante lo anterior, un civil también puede ser partícipe de un delito militar propio en virtud de la doctrina de la accesoriedad en la participación y unidad del título de imputación. Por tanto, un civil puede ser condenado como inductor, cooperador necesario o cómplice de un delito militar propio ${ }^{11}$. Así la Sentencia de 22 de febrero de 2013 del Tribunal Militar Territorial Segundo (Sevilla) condenó a dos militares (como autores) y a un civil (como cooperador necesario) de un delito consumado contra la Hacienda en el ámbito militar del art. 195 del CPM-1985 ${ }^{12}$. Al referirse al "civil", dijo la mencionada Sentencia:

"Por lo que se refiere al acusado XXXXXXX, su condición de no militar no le impide constituirse en sujeto activo de la acción, puesto que, aunque el delito sea de los llamados especiales y su condición de extraneus respecto a ella es evidente, dada la naturaleza del hecho queda incorporado de pleno al elenco de las distintas posibilidades que el Código Penal otorga a la condición de autor. Como es sabido reiterada jurisprudencia de la Sala $5^{\text {a }}$, si bien referida fundamentalmente a delitos de abuso de autoridad pero perfectamente importable al presente caso, señala que si bien a veces el agente no puede realizar los elementos del tipo, entre los que se encuentra el normativo -condición legal de militar en este supuesto-, y por tanto, no puede ser autor en el sentido del párrafo $1^{\circ}$ del art. 28 del Código Penal vigente, no es menos cierto que 'puede participar en dicho delito, en virtud de la doctrina de la accesoriedad en la participación y unidad del título de imputación referida a los

\footnotetext{
${ }^{11}$ Sentencia de la Sala 5 a del Tribunal Supremo de 16 de febrero de 1996. También podría ser condenado por su intervención en un acto preparatorio punible.

${ }^{12}$ El tipo requería que el sujeto activo fuese militar: "El militar que destruyere, deteriorare, abandonare o sustrajere, total o parcialmente, el equipo reglamentario, materiales o efectos que tenga bajo su custodia o responsabilidad por razón de su cargo o destino, será castigado con la pena de...".
} 
delitos especiales, cooperando a su ejecución con un acto necesario. $\mathrm{Y}$ como el segundo párrafo del invocado art. 28, apartado b), establece que también serán considerados autores los que cooperen a la ejecución del hecho con un acto sin el cual no se habría efectuado', en palabras de la Sentencia de 23 de enero de 2001, que sigue la doctrina anterior fijada por las de 29 de diciembre de 1999; 3 de noviembre de 1998; 23 de marzo de 1993; y 1 y 15 de febrero de 1996".

b) Durante la vigencia del estado de sitio: la Jurisdicción militar será competente para conocer de los delitos expuestos en el apartado anterior, si bien en estos casos el CPM impone al autor una pena superior, debido a las circunstancias extraordinarias del momento en que se ha cometido el delito.

Además, la Jurisdicción militar conocerá de los siguientes delitos cometidos por un civil: estragos del art. $346 \mathrm{CP}$ (art. 27 CPM), denuncia falsa de aparatos explosivos en lugares afectos a las Fuerzas Armadas o a la Guardia Civil (art. 28 CPM), incumplimiento de Bando militar (art. 30 CPM), delitos contra centinela (art. 34), delitos previstos en los arts. 550 a $556 \mathrm{CP}$ contra autoridad militar, fuerza armada o policía militar (art. 35.2 CPM), cooperación a la inutilización voluntaria y simulación para eximirse del servicio (art. $59 \mathrm{CPM}$ ) e incumplimiento contractual (art. 84 CPM).

Asimismo, la Jurisdicción militar conocerá de los delitos del CP común que disponga la declaración de estado de sitio ${ }^{13}$.

c) En caso de conflicto armado ${ }^{14}$ : la Jurisdicción militar conocerá de los delitos propios e impropios señalados en el apartado anterior, así como del delito de espionaje militar cometido por extranjero (art. 25 CPM).

\section{III. ÁMBITO SUBJETIVO DE APLICACIÓN}

Como hemos visto, la inmensa mayoría de los delitos contenidos en el Libro Segundo del CPM solo pueden ser cometidos por militares. Y el CPM se preocupa en destacar en su art. 2 qué ha de entenderse por "militar":

\footnotetext{
${ }^{13}$ Conforme a lo dispuesto en el art. 35 de la Ley Orgánica 4/1981, de 1 de junio, de los estados de alarma, excepción y sitio, "en la declaración del estado de sitio el Congreso de los Diputados podrá determinar los delitos que durante su vigencia quedan sometidos a la Jurisdicción Militar".

${ }^{14}$ El art. 13 de la Ley Orgánica 4/1987, de 15 de julio, de competencia y organización de la Jurisdicción Militar, establece la competencia de Jurisdicción militar en caso de conflicto armado.
} 
"Son militares, a efectos de este Código, quienes al momento de la comisión del delito posean dicha condición, de conformidad con las leyes relativas a la adquisición y pérdida de la misma y, concretamente, con las excepciones que expresamente se determinen en su legislación específica:

1. Los que mantengan una relación de servicios profesionales con las Fuerzas Armadas o con la Guardia Civil, mientras no pasen a alguna situación administrativa en la que tengan en suspenso su condición militar.

2. Los reservistas cuando se encuentren activados en las Fuerzas Armadas.

3. Los alumnos de los centros docentes militares de formación y los aspirantes a la condición de reservistas voluntarios en su periodo de formación militar.

4. Los alumnos pertenecientes a la enseñanza de formación de la Guardia Civil.

5. Quienes pasen a tener cualquier asimilación o consideración militar, de conformidad con la Ley Orgánica reguladora de los Estados de alarma, excepción o sitio y normas de desarrollo.

6. En las situaciones de conflicto armado o estado de sitio, los capitanes, comandantes y miembros de la tripulación de buques o aeronaves no militares que formen parte de un convoy, bajo escolta o dirección militar, así como los prácticos a bordo de buques de guerra y buques de la Guardia Civil.

7. Los prisioneros de guerra, respecto de los que España fuera potencia detenedora".

Vamos a ver cada uno de estos supuestos.

\subsection{Militares profesionales}

Según el art. 2 CPM, son militares, a efectos de dicho Código, "los que mantengan una relación de servicios profesionales con las Fuerzas Armadas (...), mientras no pasen a alguna situación administrativa en la que tengan en suspenso su condición militar". 
Conforme al art. 3.1 de la Ley 39/2007, de 19 de noviembre, de la Carrera Militar (LCM), los españoles podrán vincularse profesionalmente a las Fuerzas Armadas de una triple forma:

- Como militares de carrera.

- Como militares de complemento.

- Como militares de tropa y marinería.

Son militares de carrera quienes mantienen una relación de servicios profesionales de carácter permanente. Les corresponde asegurar la continuidad y estabilidad de la estructura, el funcionamiento y los valores esenciales de las Fuerzas Armadas en el marco constitucional.

Los militares de complemento son oficiales que establecen su relación de servicios profesionales mediante compromisos de carácter temporal para atender necesidades específicas de las Fuerzas Armadas.

Los militares de tropa y marinería, que constituyen la base de las Fuerzas Armadas, establecen su relación de servicios profesionales mediante compromisos de carácter temporal, y podrán acceder a la condición de militar de carrera en la forma que se especifica en la LCM.

Por tanto, los militares de carrera son los únicos que mantienen una relación de servicios profesionales de carácter "permanente". En cambio, los militares de complemento y los militares de tropa y marinería establecen su relación de servicios profesionales mediante compromisos de carácter "temporal".

Para determinar si un individuo ostenta la condición de militar profesional a efectos del CPM, hay que tener en cuenta si reune tal condición en el momento de la comisión del delito. Por tanto, resulta preciso determinar cuándo se adquiere la condición de militar profesional. Sobre tal cuestión, los arts. 76 y siguientes de la Ley de la Carrera Militar establecen lo siguiente:

- La condición de militar de carrera se adquiere al incorporarse a una escala de oficiales o de suboficiales con la obtención del primer empleo militar, una vez superado el plan de estudios correspondiente y obtenida la titulación exigida ${ }^{15}$.

\footnotetext{
15 También adquieren la condición de militar de carrera los militares de tropa y marinería cuando, según lo previsto en la Ley 8/2006, de 24 de abril, de Tropa y Marinería, accedan a una relación de servicios de carácter permanente.
} 
- La condición de militar de complemento se adquiere al adscribirse a una escala y cuerpo mediante la superación del plan de estudios correspondiente y firmado el compromiso inicial, con el empleo de teniente conferido por el Ministro de Defensa.

- La condición de militar de tropa y marinería se adquiere al incorporarse a una escala una vez superado el período de formación determinado en la convocatoria y firmado el compromiso inicial.

Ahora bien, no todo militar profesional, por el simple hecho de serlo, está sujeto a las leyes penales militares, sino que dependerá de su situación administrativa. El art. 107 LCM establece las siguientes situaciones ${ }^{16}$ :

a) Servicio activo.

b) Servicios especiales.

c) Excedencia, que tiene las siguientes modalidades:

- Excedencia por prestación de servicios en el sector público.

- Excedencia voluntaria por interés particular.

- Excedencia voluntaria por agrupación familiar.

- Excedencia por cuidado de familiares.

- Excedencia por razón de violencia de género.

d) Suspensión de funciones ${ }^{17}$.

e) Suspensión de empleo ${ }^{18}$.

f) Reserva.

g) Servicio en la Administración civil.

${ }^{16}$ Es de señalar que no todos los militares profesionales pueden disfrutar de esas situaciones. Por ejemplo, solo los militares de carrera pueden pasar a la situación de reserva o de servicio en la Administración civil; a la situación de servicios especiales solo pueden pasar los militares de carrera y los militares de tropa y marinería con compromiso de larga duración...

${ }^{17}$ El pase a esta situación se puede acordar como consecuencia del procesamiento, inculpación o adopción de alguna medida cautelar contra el imputado en un procedimiento penal o por la incoación de un procedimiento disciplinario por falta muy grave.

${ }^{18}$ Se pasa a esta situación por alguna de las siguientes causas:

a) Condena, en sentencia firme, a la pena de prisión del CPM o del CP, mientras se encuentre privado de libertad y sin perjuicio de lo dispuesto en la Ley Orgánica de Régimen Disciplinario de las Fuerzas Armadas, o a las penas, principal o accesoria, de suspensión militar de empleo o suspensión de empleo o cargo público.

b) Imposición de sanción disciplinaria de suspensión de empleo por falta muy grave.

El Ministro de Defensa también puede acordar el pase del militar a esta situación a la vista de la sentencia en que se impusiera la pena de inhabilitación especial para profesión, oficio o cualquier otro derecho, si dicha inhabilitación impide o menoscaba el ejercicio de sus funciones. 
Pues bien, el militar profesional está sujeto a las leyes penales militares, salvo que tenga su condición militar en suspenso. Por tanto, resulta imprescindible determinar cuándo tiene su condición militar en suspenso. La LCM establece que el militar tendrá su condición militar en suspenso durante el tiempo que permanezca en alguna de las siguientes situaciones:

a) Servicios especiales (art. 109.5 LCM)

b) Excedencia, en las siguientes modalidades:

- Excedencia por prestación de servicios en el sector público (art. 110.2 LCM).

- Excedencia voluntaria por interés particular (art. 110.3 LCM).

- Excedencia voluntaria por agrupación familiar (art. 110.4 LCM).

- Excedencia por cuidado de familiares (art. 110.5 LCM).

¿Qué ocurre en el resto de las situaciones? Resulta evidente que el militar en servicio activo está sujeto a las leyes penales militares. Y lo mismo ocurre con el militar en reserva, pues solo al pasar a retiro se deja de estar sujeto a las leyes penales militares.

Ciertamente, la LCM no dice nada sobre si están sujetos a las leyes penales militares los militares que se encuentren en las siguientes situaciones: excedencia por razón de violencia de género, suspensión de funciones, suspensión de empleo y servicio en la Administración civil. Tal laguna de la LCM ha sido colmada, en parte, por el Real Decreto 1111/2015, de 11 de diciembre, por el que se aprueba el Reglamento de adquisición y pérdida de la condición de militar y situaciones administrativas de los militares profesionales ${ }^{19}$. Según este Reglamento:

a) Situación de excedencia por razón de violencia de género: la mujer militar profesional que se encuentre en esta situación está sujeta a las leyes penales militares por disposición expresa del art. 24.2 del Reglamento, según el cual "en todas las situaciones de excedencia, excepto en la excedencia por razón de violencia de género, los militares tendrán su condición de militar en suspenso y, en consecuencia, dejarán de estar sujetos... a las leyes penales y disciplinarias militares".

b) Situaciones de suspensión de funciones y de suspensión de empleo: el Reglamento, al igual que la LCM, no dice nada al respecto. Entendemos que el militar que se encuentre en cualquiera de estas situaciones, está sujeto a las leyes penales militares por lo siguiente:

\footnotetext{
${ }^{19}$ En adelante, el Reglamento.
} 
- Porque al no decir nada la normativa citada, resulta de aplicación el art. 107.4 LCM, según el cual "el militar en cualquier situación administrativa, salvo en los casos en que así se especifica, está sujeto (...) a las leyes penales y disciplinarias militares". Por tanto, al no especificarse nada, está sujeto a las leyes penales militares.

- En estos casos, en realidad, el militar no tiene su condición militar en suspenso, sino que se encuentra privado temporalmente del ejercicio de sus funciones.

c) Situación de servicio en la Administración civil: el militar que se encuentre en esta situación no está sujeto a las leyes penales militares, conforme a lo dispuesto en el art. 36.1 del Reglamento.

En definitiva, están sujetos a las leyes penales militares los militares profesionales que se encuentren en las siguientes situaciones:

a) Servicio activo.

b) Excedencia por razón de violencia de género.

c) Suspensión de funciones.

d) Suspensión de empleo.

e) Reserva.

Una vez que el militar profesional ha pasado a retiro (en el caso de militares de carrera) o ha finalizado o resuelto su compromiso (en el caso de militares de complemento y de tropa y marinería), dejará de estar sujeto a las leyes penales militares.

\subsection{Miembros de la Guardia Civil}

Según el art. 2 CPM, son militares, a efectos de dicho Código, "los que mantengan una relación de servicios profesionales (...) con la Guardia Civil, mientras no pasen a alguna situación administrativa en la que tengan en suspenso su condición militar".

Conforme a la normativa vigente, no cabe duda de la naturaleza militar de la Guardia Civil y, en consecuencia, la condición militar de sus miembros. En este sentido, el art. 9.b) de la Ley Orgánica 2/1986, de 13 de marzo, de Fuerzas y Cuerpos de Seguridad, define a la Guardia Civil de "Instituto Armado de naturaleza militar". Por su parte, las Reales Ordenanzas para las Fuerzas Armadas, aprobadas por Real Decreto 96/2009, de 6 de febrero, dispone en el 
art. 2.2 que "dada su naturaleza militar y la condición militar de sus miembros, estas Reales Ordenanzas serán de aplicación a todos los miembros de la Guardia Civil, excepto cuando contradigan o se opongan a lo previsto en su legislación específica". Y la Ley 29/2014, de 28 de noviembre, de Régimen del Personal de la Guardia Civil, califica a la Guardia Civil en su art. 1 de "Cuerpo de Seguridad del Estado de naturaleza militar", y en su art. 3 expresa que son guardias civiles "los españoles vinculados al Cuerpo de la Guardia Civil por una relación de servicios profesionales de carácter permanente como miembros de las Fuerzas y Cuerpos de Seguridad del Estado y que, por la naturaleza militar del Instituto en el que se integran, son militares de carrera de la Guardia Civil'.

Ahora bien, a pesar de ser "militares de carrera" de la Guardia Civil, no siempre un guardia civil (o un alumno perteneciente a la enseñanza de formación de dicho Cuerpo) estará sujeto al CPM, pues esto solo ocurrirá en los siguientes supuestos (art. 1.4 CPM):

a) En tiempo de conflicto armado.

b) Durante la vigencia del estado de sitio.

c) En el cumplimiento de las misiones de carácter militar que se les encomienden.

d) Mientras se encuentren integrados en Unidades de las Fuerzas Armadas.

Fuera de estos supuestos, el CPM se aplicará a los miembros de la Guardia Civil (y a los alumnos pertenecientes a la enseñanza de formación de dicho Cuerpo) en los siguientes casos (art. 1.5 CPM):

a) Cuando se trate de acciones u omisiones constitutivas de delito militar previstas en el Título II del Libro Segundo del CPM. Es decir, los delitos contra la disciplina (sedición militar, insubordinación y abuso de autoridad).

b) Cuando se trate de delitos tipificados en los Títulos I (delitos contra la seguridad y defensa nacionales), III (delitos relativos al ejercicio de los derechos fundamentales y de las libertades públicas por los militares) y IV (delitos contra los deberes del servicio) del Libro Segundo, salvo que se tratara de acciones u omisiones encuadrables en actos propios del servicio desempeñado en el ejercicio de funciones de naturaleza policial.

Por tanto, no resulta de aplicación a la Guardia Civil el Título V del Libro Segundo del CPM (Delitos contra el patrimonio en el ámbito militar), salvo en los supuestos previstos en el art. 1.4 CPM, exclusión que no tiene fácil justificación. 
No obstante lo anterior, y al igual que ocurría con los militares profesionales, un guardia civil no siempre estará sujeto a las leyes penales militares, ni siquiera en los supuestos indicados anteriormente, sino que dependerá de su situación administrativa. El art. 87 de la Ley 29/2014, de 28 de noviembre, del Régimen del Personal de la Guardia Civil, regula las situaciones administrativas de dicho personal, que son similares a las de los militares profesionales de las Fuerzas Armadas, salvo dos diferencias:

- Contiene dos supuestos de excedencia que no se contemplan para los profesionales de las Fuerzas Armadas (ingreso por acceso directo como alumno de los centros de formación y excedencia basada en la consideración de víctima de terrorismo).

- No contempla la situación de servicio en la Administración civil.

El guardia civil está sujeto a las leyes penales militares, en los términos vistos anteriormente, salvo que tenga su condición de guardia civil en suspenso. Por tanto, y al igual que ocurría con los profesionales de las Fuerzas Armadas, resulta necesario determinar cuándo tiene su condición de guardia civil en suspenso. La Ley 29/2014 establece que el guardia civil tendrá su condición de guardia civil en suspenso durante el tiempo que permanezca en alguna de las siguientes situaciones:

a) Servicios especiales (art. 89.5 de la Ley 29/2014).

b) Excedencia, en las siguientes modalidades:

- Excedencia por prestación de servicios en el sector público (art. 90.2 de la Ley 29/2014).

- Excedencia voluntaria por interés particular (art. 90.3 de la Ley 29/2014).

- Excedencia voluntaria por agrupación familiar (art. 90.4 de la Ley 29/2014).

- Excedencia por cuidado de familiares (art. 90.5 de la Ley 29/2014).

Del estudio de la Ley 29/2014, de 28 de noviembre, del Régimen del Personal de la Guardia Civil, y del Real Decreto 728/2017, de 21 de julio, por el que se aprueba el Reglamento de adquisición y pérdida de la condición de guardia civil y de situaciones administrativas del personal de la Guardia Civil, se puede afirmar que están sujetos a las leyes penales militares, en los términos expuestos anteriormente, los guardias civiles que se encuentren en las siguientes situaciones: 
a) Servicio activo.

b) Excedencias en las siguientes modalidades:

- Excedencia por razón de violencia de género.

- Ingreso por acceso directo como alumno de los centros de formación.

- Excedencia basada en la consideración de víctima de terrorismo.

c) Suspensión de funciones.

d) Suspensión de empleo.

e) Reserva.

\subsection{Reservistas}

Según el art. 2 CPM, son militares, a efectos de dicho Código, "los reservistas cuando se encuentren activados en las Fuerzas Armadas".

El art. 3.7 LCM establece que adquieren condición militar, sin que su vinculación sea una relación de servicios profesionales, los reservistas cuando se incorporen a las Fuerzas Armadas, según lo previsto en el Título VI de dicha Ley.

La LCM establece las siguientes clases de reservistas:

a) Reservistas voluntarios: los españoles que habiendo solicitado participar en la correspondiente convocatoria, resulten seleccionados y superen los períodos de formación militar que se determinen para adquirir tal condición.

b) Reservistas obligatorios: en situaciones de crisis, si el Consejo de Ministros prevé que las necesidades de la Defensa Nacional no puedan ser satisfechas con los efectivos de militares profesionales, reservistas voluntarios y reservistas de especial disponibilidad, podrá solicitar al Congreso de los Diputados autorización para la declaración general de reservistas obligatorios.

c) Reservistas de especial disponibilidad: militares de tropa y marinería que adquieren dicha condición al finalizar su compromiso de larga duración con las Fuerzas Armadas al cumplir los 45 años de edad. 
Un reservista no siempre está sujeto al CPM. El art. 2 CPM contiene una precisión muy importante: estos reservistas solo estarán sujetos al CPM "cuando se encuentren activados en las Fuerzas Armadas". Pues bien:

- El art. 131 LCM regula la activación de los reservistas voluntarios.

- El art. 139 LCM regula la activación de los reservistas obligatorios.

- El art. 18 de la Ley 8/2006, de 24 de abril, de Tropa y Marinería, regula la activación de los reservistas de especial disponibilidad.

\subsection{Alumnos}

Según el art. 2 CPM, son militares, a efectos de dicho Código:

- Los alumnos de los centros docentes militares de formación y los aspirantes a la condición de reservistas voluntarios en su periodo de formación militar.

- Los alumnos pertenecientes a la enseñanza de formación de la Guardia Civil.

Resulta preciso distinguir tres supuestos:

a) Alumnos de los centros docentes militares de formación: los que ingresen en los centros docentes militares de formación, firmarán, al hacer su presentación, un documento de incorporación a las Fuerzas Armadas ${ }^{20}$. A partir de dicho momento tendrán condición militar, sin quedar vinculados por una relación de servicios profesionales, quedando sujetos a las leyes penales militares (art. $67 \mathrm{LCM}$ ).

b) Aspirantes a la condición de reservistas voluntarios: los aspirantes a reservistas voluntarios realizan un período de formación militar básica en un centro de formación, y posteriormente un período de formación militar específica en una unidad, centro u organismo del Ministerio de Defensa (art. 127 LCM). Desde el momento en que se inicia su formación, están sujetos al CPM.

c) Alumnos pertenecientes a la enseñanza de formación de la Guardia Civil: el art. 47 de la Ley 29/2014 dispone que los que ingresen en los centros docentes de formación de la Guardia Civil, al hacer su presentación, firmarán un documento de incorporación a la Guardia Civil ${ }^{21}$, y serán

\footnotetext{
${ }^{20}$ Salvo aquellos que ya pertenezcan a las Fuerzas Armadas.

${ }^{21}$ Salvo aquéllos que ya pertenezcan a dicho Cuerpo.
} 
nombrados alumnos. La Ley 29/2014 no dice nada sobre si estos alumnos están sujetos a las leyes penales militares (solo dice que estarán sujetos a las leyes disciplinarias propias de la Guardia Civil), pero no cabe duda de su sometimiento al CPM conforme a lo dispuesto en el art. 2 de dicho Código, si bien en los términos impuestos por los arts. 1.4 y 1.5 CPM.

\subsection{Personal asimilado o con consideración militar}

Según el art. 2 CPM, son militares, a efectos de dicho Código, "quienes pasen a tener cualquier asimilación o consideración militar, de conformidad con la Ley Orgánica reguladora de los estados de alarma, excepción o sitio y normas de desarrollo". Por tanto, se requiere que en la declaración del estado de alarma, excepción o sitio se proceda a tal militarización del personal civil.

La posibilidad de militarizar a personal civil en una situación excepcional, ya ha sido puesta en práctica en el año 2010. Ante el abandono de su puesto de trabajo de los controladores aéreos la tarde del 3 de diciembre de 2010, y que provocó el cierre del espacio aéreo español, el Gobierno, mediante Real Decreto 1611/2010, de 3 de diciembre, encomendó transitoriamente al Ministerio de Defensa las facultades de control de tránsito aéreo atribuidos a la entidad AENA. Y mediante Real Decreto 1673/2010, de 4 de diciembre, se declaró el estado de alarma para la normalización del servicio público esencial del transporte aéreo. En el art. 3 de este último Real Decreto se establecía que todos los controladores de tránsito aéreo al servicio de AENA pasaban a tener, durante la vigencia del estado de alarma, la consideración de personal militar, y en consecuencia, quedaban sometidos a las órdenes directas de las autoridades militares designadas en el Real Decreto, y a las leyes penales y disciplinarias militares.

3.6. Capitanes, Comandantes y miembros de la tripulación de buques o aeronaves no militares, y prácticos a bordo de buques de guerra y buques de la Guardia Civil

Según el art. 2 CPM, son militares, a efectos de dicho Código, "en las situaciones de conflicto armado o estado de sitio, los capitanes, comandantes y miembros de la tripulación de buques o aeronaves no militares que formen parte de un convoy, bajo escolta o dirección militar, así como los prácticos a bordo de buques de guerra y buques de la Guardia Civil".

Resulta preciso distinguir los siguientes supuestos: 
a) Capitanes de buque, comandantes de aeronave y tripulación de buques o aeronaves no militares: estos sujetos son militares, a efectos del CPM, cuando concurren los siguientes requisitos:

1. Que exista conflicto armado o estado de sitio.

2. Que estos buques o aeronaves formen parte de un convoy.

3. Que el convoy se encuentre bajo escolta o dirección militar.

b) Prácticos: los prácticos son militares, a efectos del CPM, cuando concurren los siguientes requisitos:

1. Que exista conflicto armado o estado de sitio.

2. Que el práctico se encuentre a bordo de un buque.

3. Que se trate de un buque de guerra ${ }^{22}$ o de la Guardia Civil ${ }^{23}$.

\subsection{Prisioneros de guerra}

Según el art. 2 CPM, son militares, a efectos de dicho Código, "los prisioneros de guerra, respecto de los que España fuera potencia detenedora".

El art. 82 del III Convenio de Ginebra, de 12 de agosto de 1949, relativo al trato debido a los prisioneros de guerra, establece que los prisioneros de guerra estarán sometidos a las leyes, los reglamentos y las órdenes generales vigentes en las Fuerzas Armadas de la Potencia detenedora, y que esta se encuentra autorizada a tomar medidas judiciales (o disciplinarias) con respecto a todo prisionero de guerra que haya cometido una infracción contra tales leyes, reglamentos u órdenes generales.

Y en el art. 84 de dicho Convenio se establece que únicamente los tribunales militares pueden juzgar a un prisionero de guerra, a no ser que en la legislación de la Potencia detenedora se autorice expresamente que los tribunales civiles juzguen a un miembro de las Fuerzas Armadas de dicha Potencia por una infracción similar a la causante de la acusación contra el prisionero.

${ }^{22}$ La Convención de Jamaica (o Convención de las Naciones Unidas sobre el Derecho del Mar, de 1982, ratificada por España) define el buque de guerra, a efectos de tal Convención, como "todo buque perteneciente a las fuerzas armadas de un Estado que lleve los signos exteriores distintivos de los buques de guerra de su nacionalidad, que se encuentre bajo el mando de un oficial debidamente designado por el gobierno de ese Estado cuyo nombre aparezca en el correspondiente escalafón de oficiales o su equivalente, y cuya dotación esté sometida a la disciplina de las fuerzas armadas regulares".

${ }^{23}$ Los buques de la Guardia Civil no son buques de guerra (que solo dispone de ellos las Fuerzas Armadas), sino buques de Estado. 


\section{CONCLUSIONES}

1. Son delitos militares las acciones $\mathrm{u}$ omisiones dolosas o imprudentes previstas en el Libro Segundo del Código Penal Militar (art. 9.1 CPM), así como ciertos delitos del Código Penal común cometidos por un militar (art. 9.2 CPM).

2. El CPM no se aplica solo a los militares, sino también a personal no militar, y no solo en caso de estado de sitio o de conflicto armado, sino también en tiempos de paz.

3. Los militares profesionales solo están sujetos a las leyes penales militares si su condición militar no está en suspenso.

4. Los miembros de la Guardia Civil están sujetos al CPM en los términos previstos en los arts. 1.4 y 1.5 de dicho Código, y siempre que no tengan su condición de guardia civil en suspenso.

5. Los reservistas solo están sujetos al CPM cuando se encuentran activados. Los aspirantes a reservistas voluntarios están sujetos al CPM desde el momento en que se inicie su formación.

6. Los alumnos de los centros docentes militares de formación y los alumnos pertenecientes a la enseñanza de formación de la Guardia Civil están sujetos al CPM, si bien estos últimos en los términos impuestos por los arts. 1.4 y 1.5 CPM.

7. El personal asimilado o con consideración militar, conforme a la declaración del estado de alarma, excepción o sitio, está sujeto al CPM.

8. Los capitanes de buque, comandantes de aeronave y tripulación de buques o aeronaves no militares, así como los prácticos, están sujetos al CPM en los términos establecidos en el art. 2 CPM.

9. A los prisioneros de guerra se les aplica el CPM en el caso de que España sea potencia detenedora.

\section{BIBLIOGRAFÍA}

- BLECUA FRAGA R., y RODRÍGUEZ-VILLASANTE Y PRIETO, J.L. (coords.), Comentarios al Código Penal Militar, Madrid 1988.

- CALDERÓN CEREZO, A., "Delimitación Constitucional de la Jurisdicción Militar", en La Ley Penal no 98 (noviembre, 2012). 
- CALDERÓN SUSÍN, E., "Comentario de urgencia al Proyecto de Código Penal Militar", en Cuadernos de la Facultad de Derecho de la Universidad de Palma de Mallorca, ${ }^{\circ} 9$ (1984).

- DE LEÓN VILLALBA, F.V.; JUANES PECES, A., y RODRÍGUEZVILLASANTE Y PRIETO, J.L. (Dirs.), El Código Penal Militar de 2015, Valencia 2017.

- FERNÁNDEZ SEGADO, F., "La reforma del ámbito competencial de la Jurisdicción Militar", en Cuadernos de estrategia, nº 50 (1992).

- PÉREZ ESTEBAN, F. "La competencia de la jurisdicción militar: lo estrictamente castrense", en La Ley Penal n 7, julio 2004.

- QUEVEDO GONZÁLEZ, J., "El civil ante la Jurisdicción Militar: especial referencia a los delitos contra los medios o recursos de la Defensa Nacional", en Jornadas de especialistas en la jurisdicción militar, enero 2018.

- RODRÍGUEZ-VILLASANTE Y PRIETO, J.L., "El Código Penal Militar", en Revista General de Derecho, no 499 (1986).

- RODRÍGUEZ-VILLASANTE Y PRIETO, J.L., "La reforma de la organización de la justicia militar española en la transición y consolidación democrática", en La albolafia: revista de humanidades y cultura, $\mathrm{n}^{\circ} 14$ (2018).

- VALENCIANO ALMOYNA, J., "La reforma de la justicia militar en España durante la Transición", en Revista Española de Investigaciones Sociológicas (REIS), Madrid, $\mathrm{n}^{\circ} 36$ (1986). 
